\title{
LA INCLUSIÓN DE LAS NUEVAS GENERACIONES EN CONTEXTOS DE DESIGUALDAD E INCERTIDUMBRE: PERSPECTIVAS EDUCATIVAS Y LABORALES EN AMÉRICA LATINA Y EL CARIBE
}

\author{
Dr. Pablo Christian Aparicio Castillo \\ Universtität Heidelberg, \\ Pädagogische Hochschule Ludwisburg \\ \& Universität Tübingen
}

\begin{abstract}
RESUMEN
La globalización ha desencadenado procesos y dinámicas de transformación social, económica y política con un fuerte carácter excluyente y homogeneizante. En América Latina, se encararon entre los años 2002 y 2012 múltiples reformas políticas orientadas a la recuperación de una agenda social, a la compensación de las desigualdades socioeconómicas y a la visibilización de la diversidad identitaria y cultural, que salvo algunas excepciones, pudieron concretarse efectivamente. Uno de los tópicos más preponderantes de las reformas políticas, se ha centrado en la educación como medio estratégico, para reparar las deudas sociales estructurales, y así, potenciar el desarrollo de modelos y propuestas acordes a las demandas de los contextos locales y a las tendencias globales de desarrollo. El presente artículo analiza la participación de las nuevas generaciones en el ámbito educativo y laboral, ámbito donde se han implementado diversas reformas que han impactado con serias limitaciones en el mejoramiento de las condiciones de vida de las personas.
\end{abstract}

Palabras claves: Globalización; Educación; Trabajo; Inclusión social; Desigualdad; América Latina.

\section{THE INCLUSION OF NEW GENERATIONS \\ IN CONTEXTS OF INEQUALITY AND UNCERTAINTY: EDUCATIONAL AND LABOR PERSPECTIVES IN LATIN AMERICA AND THE CARIBBEAN}

\begin{abstract}
Globalization has within unleashed processes and dynamics of social, economic and political transformation with a strong exclusionary and homogenizing character. In Latin America, multiple political public reforms have been carried out in the last 15 years. These were aimed to recover a local social political agenda, the compensation of socioeconomic inequalities, and the visibility of cultural diversity identity. Which, with a few exceptions, were effectively achieved. One of the most important topics of political reforms has been focused on education as an strategic mean to repair structural social debts and also to promote the development of models and proposals according to the demands of local contexts and global development trends. The present article analyzes the participation of the new generations in the educational and labor field, where several reforms have been implemented that have had serious limitations in the improvement of the living conditions of the people.
\end{abstract}

Keywords: Globalization; Education; Work; Social inclusion; Inequality; Latin America. 


\section{Introducción}

La crisis del modelo neoliberal registrada en América Latina y en el mundo occidental capitalista, ha estado marcada por el fracaso de la ortodoxia económica tecnocrática practicada por el modelo político neoconservador el cual, basado en la idea del libre mercado, ha reabierto el debate sobre la necesidad de recuperar las injerencias directas del Estado en materia de política social pública, a la hora de atemperar el impacto de la pobreza, la desigualdad económica y la vulnerabilidad social e institucional, pero fundamentalmente, para hacer frente a la ausencia e inconsistencia de una política transnacional, capaz de atemperar y regular la deuda financiera privada y la insolvencia bancaria que han potenciado los recientes conflictos económicos, financieros y sociales.

Después de la debacle económica y social producida en diversos países de América Latina a partir del año 2000 y hasta el 2012, se implementaron en la región diferentes políticas públicas novedosas de cobertura universal, las cuales buscaron propiciar procesos de inclusión social, capaces de mitigar la polarización y la desagregación social. En este marco de condiciones, se volvió a plantear la necesidad de reorientar el sentido de la propuesta educativa, basada en los criterios de inclusión universal, compensación de las desigualdades y atención contextual de las nuevas demandas y urgencias sociales.

En la actualidad, el carácter contradictorio y especulativo de la política económica global, subyace en el fundamento mismo de la transformación de contextos y procesos sociales, culturales y ecológicos que, indudablemente, modifican el modo en cómo las sociedades y los Estados en América Latina definen estrategias y conceptos para afrontar los desafíos que imponen las complejas realidades.

A través de la globalización, se dinamizan diversos procesos de exclusión y fragmentación social y económica que, parecen estar fuertemente enraizados en una competencia de todos contra todos, en el individualismo y en el consecuente desmedro de procesos sociales sostenidos en valores como la solidaridad, la diversidad y la cooperación. Del mismo modo, la expansión de la precariedad y el riesgo social como condición social inmanente, así como también, la fragmentación de lo público y la exaltación del monopolio privado, la incertidumbre y la inseguridad permanente como condiciones inherentes a la organización de la vida colectiva; el ensimismamiento y la dilación de los nexos de cohesión social.

Con la asunción de gobiernos de orientación política progresista en la región (pos hegemonía Neoliberal), se planteó una reorientación política e ideológica considerable, que contribuyó a recuperar el sentido democratizador e incluyente de los programas y de las acciones sociales fundamentalmente en el ámbito educativo.

Con esta idea transformadora, se intentó redimensionar los modelos y procesos pedagógicos preexistentes, con la intención de convertir a la educación en un medio de promoción y desarrollo social, capaz de mejorar los niveles de integración y bienestar socioeconómico general.

Pero es de aquí que los esfuerzos depositados en focalizar la inversión social y así poder atemperar la reproducción de las brechas socioeconómicas y el acceso desigual a la educación, al trabajo productivo y a los servicios sociales, no se resultado efectivas al momento de contrarrestrar la reproducción de las causas originarias de estos problemas. Vale decir, con la inyección de fondos públicos y la tranposición de programas educativos innovadores sin una debida estrategia sinérgica y procesual ha resultado insatisfactoria.

Indudablemente, esta situación repercute en la vida de las sociedades y transforma los sistemas de representación social, la disposición subjetiva de los actores y la valoración que éstos realizan acerca de la impronta de la educación en torno a sus propios proyectos 
individuales y la modificación de la situación socio-histórica en la que se encuentran circunscriptos.

En la región existe un amplio acuerdo en afirmar que la participación en la educación puede favorecer las condiciones y las posibilidades de inclusión social, y con este razonamiento, se apostó por el incremento de las dotaciones presupuestarias y la redefinición de la agenda política, después de que, por casi 10 años, fuera practicado un tecnicisimo cortoplacista al momento de elaborar las políticas del sector.

Sin embargo, todavía prevalece una distribución inequitativa de las ofertas educativas, desde donde se socializan de forma diferenciada competencias, conocimientos y disposiciones cognitivas, sociales y técnicas, las cuales repercuten significativamente en el desarrollo de las personas a nivel biográfico y colectivo.

En el presente artículo se analizará el impacto que han tenido las políticas educativas de reciente implementación en la región, en lo referido al dimensionamiento de las necesidades, los contextos y las características socioculturales de las generaciones más jóvenes y a la mejora de las posibilidades reales de participación social.

\section{Eclipse neoliberal y Estado social: el reflote de las políticas e intervenciones públicas.}

El impacto de los procesos económicos globales, los avances tecnológicos y científicos, el desarrollo de estrategias complejas de comunicación y producción material y simbólica, la transformación de los procesos de socialización, integración e interacción intercultural y el afianzamiento del binomio constituido por la democracia (como modelo político de gobierno) y el capitalismo globalizado (como modelo económico, productivo y laboral) han traido consigo cambios paradigmáticos.

Al día de hoy, estamos situados en una de las crisis más profundas de la economía de libre mercado y del modelo neoliberal que ha sido provocada por el carácter falaz de la política financiera, la escasa transparencia y efectividad de los mecanismos de regulación y liberalización del mercado a nivel nacional y de las políticas económicas transnacionales.

En esta coyuntura, se ha puesto al descubierto la incapacidad del sector privado para posibilitar un tipo de desarrollo social incluyente y sostenible. La ruptura entre los intereses y las prioridades económicas y las demandas sociales, expusieron la importancia del Estado y su implicancia en el sostenimiento de la cohesión social, y así también, su rol en el salvataje de un sistema económico - bancario desbocado, que ha transformado flagrantemente la deuda privada en deuda pública.

Una de las mayores paradojas del modelo neoliberal en torno a la independencia y autosuficiencia del mercado como único regulador de las interacciones sociales y promotor del desarrollo y del crecimiento económico, estriba en que, por una parte, se aboga por el cese de la intervención desmedida del Estado en el ámbito de la gestión y el financiamiento de los servicios sociales basados en la privatización de los servicios públicos, la liberalización del mercado de trabajo y la apertura económica y comercial. Pero, por otra parte, sin embargo, en momentos de recesión económica y de retracción del flujo de los capitales privados y la disminución de las ganancias e inversiones que sostienen las economías locales, se recurre de forma inmediata a la ayuda del Estado, y esto, a través de la destinación de fondos públicos para accionar el rescate y el pago de las deudas privadas. De este modo, en un contexto de hegemonía de un liberalismo económico exacerbado, el Estado y lo público aparecen nuevamente como herramientas estratégicas para sopesar irregularidades finacieras, dinamizar circuitos productivos y velar por el resguardo de la cohesión social en tiempos de inflexión, recesión y crisis económica. 
En la versión más rígida del neoliberalismo implementada en algunos países de América Latina y el Caribe durante los años '90, se apostó por la eliminación progresiva del Estado y su facultad de intervenir y regular la dinámica de la política económica. En cambio ahora, cicunscriptos en una coyuntura global donde los cánones fundantes de la economía del libre mercado parecen tambalear y contradecirse dentro de las economías más industrializadas, allí es cuando se exalta la importancia de retomar la política pública para contrarrestar el estancamiento dominante en las áreas de economía, empleo y seguridad bienestar social.

La revalorización del Estado y su implicación directa en la gestión y la regulación política de lo público y lo colectivo, vuelve a plantearse como una estrategia pertinente y necesaria para resolver problemas profundos de índole social, económica e institucional.

Con la reconsideración de la importancia del Estado como actor estratégico del desarrollo por parte de las economías más poderosas del globo y de sus antigüos referentes (entidades financieras y bancarias internacionales, accionistas, inversores, empresas e industrias multinacionales), se observa que las prioridades de las agendas políticas, aún se resisten a comprometerse con la construcción de condiciones económicas, ecológicas y laborales más sustentables y democráticas para las sociedades. Por lo opuesto, se continúa insistiendo en la creencia del impacto expansivo de los beneficios del modelo económico y productivo, prescindiendo de la elaboración de estrategias políticas que hagan eje en la superación de las restricciones estructurales (MALDONADO VARELA \& PALMA ROCCO, 2013).

En este contexto, la desigualdad social y económica todavía imperante en la región, se debe por un lado, a la distribución inequitativa del ingreso, a la acumulación de la riqueza, a la falta de oportunidades laborales productivas, a las brechas en los índices de bienestar y a la débil transparencia política e institucional. Por otro lado, este problema estructural se plantea como causa y consecuencia del acceso restringido y diferenciado a la formación educativa, a los activos productivos, a los servicios sociales y al trabajo productivo, tan significativos para la participación plena en la vida social y la objetivación de los derechos ciudadanos (LÓPEZ-CALVA \& LUSTIG, 2010; CECHINI \& MARTÍNEZ, 2011).

Los datos estadísticos proporcionados por la CEPAL (2010) sobre el impacto de la pobreza y de la indigencia entre jóvenes de 15 a 29 años, permiten constatar que las categorías ligadas al sexo, la pertenencia étnica - cultural y el área de residencia, son distintivas entre los jóvenes. En este sentido, los grupos más afectados por la pobreza y la indigencia son preponderamente mujeres indígenas residentes en zonas rurales. 


\section{Cuadro $\mathbf{N}^{\circ} \mathbf{1}^{1}$ \\ Dieciocho países de América Latina y el Caribe: \\ Incidencia de la pobreza y de la indigencia entre jóvenes de 15 a 29 años clasificados por sexo, grupo étnico y área de residencia, entre marzo y octubre de 2009 (En porcentajes)}

\begin{tabular}{|c|c|c|c|c|c|c|c|c|c|c|c|c|c|}
\hline \multirow[b]{2}{*}{ Países } & \multirow[b]{2}{*}{ Año } & \multicolumn{6}{|c|}{$\begin{array}{c}\text { Jóvenes en situación } \\
\text { de pobreza de } 15 \text { a } 29 \text { años }\end{array}$} & \multicolumn{6}{|c|}{$\begin{array}{l}\text { Jóvenes en situación } \\
\text { de Indigencia de } 15 \text { a } 29 \text { años }\end{array}$} \\
\hline & & Hombres & Mujeres & Indigenas & $\begin{array}{c}\text { No } \\
\text { Indígenas }\end{array}$ & $\begin{array}{l}\text { Áreas } \\
\text { Urbanas }\end{array}$ & $\begin{array}{l}\text { Áreas } \\
\text { Rurales }\end{array}$ & Hombres & Mujeres & Indigenas & $\begin{array}{c}\text { No } \\
\text { Indígenas }\end{array}$ & $\begin{array}{l}\text { Áreas } \\
\text { Urbanas }\end{array}$ & $\begin{array}{l}\text { Áreas } \\
\text { Rurales }\end{array}$ \\
\hline ARGENTINA a/ & 2009 & 10,6 & 13,0 & & & 11,8 & & 3,4 & 4,3 & & & 3,9 & \\
\hline EST. PLUR. DE BOLIVIA & 2007 & 47,2 & 51,5 & 58,2 & 42,9 & 41,6 & 67,8 & 25,7 & 27,7 & 36,4 & 19,5 & 15,8 & 52,2 \\
\hline BRASIL & 2009 & 22,9 & 26,9 & 30,2 & 24,5 & 22,1 & 40,2 & 5,8 & 7,2 & 7,9 & 6,4 & 5,1 & 14,7 \\
\hline CHILE & 2009 & 11,1 & 13,3 & 16,3 & 11,9 & 12,3 & 11,6 & 3,2 & 4,1 & 6,3 & 3,5 & 3,5 & 4,9 \\
\hline COLOMBIA & 2009 & 41,5 & 45,7 & $\ldots$ & ... & 38,4 & 61,2 & 12,7 & 15,4 & $\ldots$ & & 10,8 & 25,0 \\
\hline COSTA RICA & 2009 & 14,4 & 18,4 & & & 16,6 & 16,0 & 5,0 & 6,5 & & $\ldots$ & 4,4 & 7,6 \\
\hline ECUADOR & 2009 & 36,2 & 42,0 & 53,9 & 37,3 & 37,6 & 42,2 & 14,6 & 16,9 & 30,7 & 13,9 & 13,4 & 20,9 \\
\hline EL SALVADOR & 2009 & 43,9 & 47,2 & & & 41,2 & 53,0 & 14,7 & 15,8 & & $\ldots$ & 11,3 & 21,9 \\
\hline GUATEMALA & 2006 & 47,8 & 51,8 & 67,8 & 39,5 & 38,9 & 61,3 & 21,8 & 25,2 & 40,7 & 13,7 & 11,7 & 35,9 \\
\hline HONDURAS & 2007 & 62,5 & 63,5 & $\ldots$ & $\ldots$ & 51,6 & 74,2 & 38,7 & 38,9 & $\ldots$ & $\ldots$ & 20,8 & 56,3 \\
\hline MÉXICO & 2008 & 29,1 & 34,4 & & & 27,1 & 40,7 & 8,2 & 10,5 & & & 5,4 & 16,9 \\
\hline NICARAGUA & 2005 & 57,6 & 59,0 & 70,2 & 57,7 & 50,9 & 68,6 & 28,7 & 27,7 & 44,2 & 27,5 & 17,8 & 42,7 \\
\hline PANAMÁ & 2009 & 21,7 & 25,4 & 70,2 & 20,1 & 15,0 & 40,3 & 8,4 & 10,3 & 38,7 & 7,2 & 4,3 & 19,3 \\
\hline ParaguaY & 2009 & 50,5 & 50,7 & 72,1 & 38,3 & 42,7 & 63,4 & 25,9 & 25,0 & 46,5 & 13,5 & 14,8 & 42,7 \\
\hline PERÚ & 2009 & 29,8 & 31,1 & 58,9 & 26,3 & 19,6 & 54,4 & 8,0 & 9,4 & 25,6 & 6,2 & 2,3 & 22,8 \\
\hline REP. DOMINICANA & 2009 & 36,4 & 39,9 & $\ldots$ & $\ldots$ & 37,1 & 40,4 & 16,5 & 19,5 & $\ldots$ & $\ldots$ & 16,7 & 20,6 \\
\hline URUGUAY & 2009 & 10,2 & 12,0 & $\ldots$ & $\ldots$ & 11,5 & 5,4 & 1,9 & 2,3 & $\ldots$ & $\ldots$ & 2,2 & 1,3 \\
\hline REP. BOL. DE VENEZUELA & 2008 & 22,5 & 27,4 & $\ldots$ & $\ldots$ & $\ldots$ & $\ldots$ & 7,0 & 9,7 & $\ldots$ & $\ldots$ & $\ldots$ & $\ldots$ \\
\hline $\begin{array}{l}\text { AMÉRICA LATINA } \\
\text { PROMEDIO PONDERADO }\end{array}$ & & 28,2 & 32,4 & 47,0 & 26,4 & 25,5 & 46,8 & 9,2 & 11,0 & 22,9 & 7,7 & 6,5 & 21,9 \\
\hline
\end{tabular}

Como se tiene dicho, este contexto social crítico, repercute en la vida de las sociedades y transforma la disposición subjetiva de los actores, así como la valoración que éstos realizan en torno a la importancia de la educación, del trabajo, de los proyectos colectivos y de los modelos de desarrollo e inclusión social. En especial modo, los niños y los jóvenes de América Latina, constituyen los grupos más vulnerables, a la hora de padecer la falta de alternativas de inclusión social en el ámbito político público, el desplome de los modelos de desarrollo y referencia intergeneracional que solían garantizar a largo plazo la transición desde los sistemas educativos hacia el mercado laboral y la vida adulta, la ausencia de interlocutores políticos e institucionales capaces de vincular / referenciar las trayectorias, las experiencias y los itinerarios de los más jóvenes y el desmembramiento de las redes e instituciones de contención social (CEPAL, OIJ \& IMJUVE, 2014).

Todos estos fenómenos se hallan circunscriptos dentro de un escenario histórico fuertemente influenciado por el individualismo fragmentado, la competitividad extrema, la liquidez inmanente de los vínculos socioafectivos, la imprevisibilidad de los procesos económicos y sociales, el riesgo y la vulnerabilidad como condición subyacente del devenir socioeconómico, el consumismo como ilusión de inclusión y la fragmentación reduccionista de la cultura en el contexto de la globalización (BAUMAN, 1993, 2001; CASTEL, 1999; BECK \& BECK-GERNSCHEIM, 2007).

Por todo lo señalado, resulta legítimo cuestionarse en América Latina cuál es el sentido incluyente que tienen hoy las políticas implementadas en los diferentes ámbitos de la vida social y que han estado destinadas a atender las demandas más urgentes de los distintos grupos sociales, quienes aparecen cada vez más polarizados y desmembrados, y que por el mismo motivo, están necesitados de una verdadera visibilización, así como de un apoyo que repare en las características de sus entornos de vida y coadyuve a superar las 
dificultades inherentes a los procesos de participación social (de HOYOS, ROGERS y SZÉKELY, 2016).

\section{La exclusión y la desigualdad educativa en América Latina}

En América Latina se evidencia que el acceso a la educación de calidad, al desarrollo del conocimiento científico, a los insumos tecnológicos y a los diferentes ámbitos estratégicos de la cultura adquieren una influencia determinante en la organización de la vida colectiva y la orientación de los procesos de producción, acumulación y distribución social de bienes materiales y simbólicos.

A partir de la introducción de las nuevas reformas educativas se han incorporado postulados políticos, educativos y curriculares orientados a mejorar el acceso y la culminación de los procesos de formación de calidad. Con ello, se pretendía optimizar la dotación de recursos profesionales, materiales y tecnológicos a los fines de garantizar la trasposición adecuada de nuevos contenidos curriculares, la innovación tecnológica constante, el desarrollo científico local, la cooperación inter y transinstitucional y la empoderización de las competencias autónomas de gestión institucional educativa (GENTILI, 2009).

En este sentido, entre los años 2000 y 2013 se evidencia para la región un incremento progresivo de las tasas de escolarización en todos los niveles del sistema educativo que ha posibilitado el acompañamiento del aumento demográfico y además ha repercutido positivamente en la disminución de las brechas de género dentro del sistema escolar (Aparicio, 2014).

Pese a este panorama alentador, en la mayor parte de los países de la región más del $10 \%$ de los niños y niñas que, por su edad, deberían estar cursando la escuela primaria aún no están escolarizados (MORDUCHOWICZ y DURO, 2007). Por otro lado, el incremento de los años de estudio de los jóvenes comprendidos entre 18 y 24 años no ha implicado todavía la mejora y/o superación de las condiciones socioeconómicas que afectan a los sectores sociales más desfavorecidos. Por el contrario, el aumento del nivel educativo se ha concretado primordialmente entre los grupos juveniles más acomodados, fenómeno que guarda una cierta correlación con el nivel educativo alcanzado por los progenitores y el nivel socioeconómico prevaleciente. Hecho que viene a demostrar la persistencia de una reproducción intergeneracional de las desigualdades educativas y socieconómicas (UNESCO, 2012).

En referencia a algunos estudios elaborados sobre la reproducción de las inequidades sociales se podría sostener que una de sus manifestaciones más elocuentes en América Latina se materializa en los logros educativos diferenciados que conllevan a su vez la reproducción de trayectorias laborales y sociales diferenciadas (Ocampo, 2008; Cecchini \& Madariaga, 2011). Por ejemplo, si se ponderan los datos correspondientes al egreso de la educación secundaria completa y a la asistencia a la educación terciaria (universitaria y no universitaria) se puede constatar que son principalmente los sectores medios y altos quienes tienen garantizados el acceso a estos dos eslabones tan importantes de la formación educativa (GASPARINI et al., 2009).

La desigualdad en el acceso a la educación que se constata entre los diferentes grupos sociales (ricos y pobres) que afecta sobre todo a las minorías étnico - culturales, no sólo condiciona la capacidad de desarrollar de forma autónoma los diferentes proyectos de vida, sistematizar las propias demandas e intereses y representar el mundo, sino que también, 
altera el modo en cómo estos sujetos son visibilizados por el mundo social en el cual habitan y se perciben a sí mismos en sus espacios de vida (UNICEF \& UNESCO, 2012).

En consecuencia, la injusticia, la desigualdad y la fragmentación dentro del ámbito educativo todavía operan en la forma en cómo se distribuye y apropian las ofertas de formación (Aparicio, 2010). Con todo, la depreciación de los programas y las deplorables condiciones tecnológicas, edilicias y profesionales sobre las que se erigen las propuestas pedagógicas afectan el impacto social de la participación en el conocimiento y en la cultura y repercute preponderantemente en la proyección biográfica - cognitiva, la construcción identitaria y la capacidad de gestión de las propias competencias al momento de superar conflictos.

A pesar de que en la mayoría de los países de la región exista un amplio concierto de programas y políticas destinadas a proveer "ayudas sociales" a los grupos más rezagados y en situación de riesgo social, también es cierto que, por ejemplo, en el ámbito educativo las trayectorias escolares de los alumnos más pobres se siguen interrumpiendo o suelen ser deficitarias en comparación con sectores no pobres y socialmente más incluidos, lo que relativiza el impacto favorable que han tenido estos emprendimientos públicos.

Por ende, pensando en términos de equiparación de las posibilidades de participación social plena, podemos sostener que para mejorar las condiciones de participación educativa no basta sólo con fomentar el acceso a la escuela, sino mucho más, se requiere acompañar las trayectorias educativas y sostener en el tiempo la mejora de la participación y la conclusión de los ciclos escolares, que debería conllevar una optimización de la calidad de las ofertas de formación y el desenvolvimiento ulterior de las personas en el medio social, laboral y cultural.

En el ámbito de las reformas de las políticas públicas se ha insistido en focalizar el gasto social público con la intención de efectivizar la inversión educativa desde una perspectiva local y descentralizada, empero a ello, en la práctica se observa que los efectos alcanzados por estas medidas han acentuado la fragmentación del sistema educativo, puesto que se tendió sistemáticamente a ofrecer a sectores desaventajados y en riesgo social, ofertas de formación suplementarias y asistencialistas de calidad preeminentemente baja que, sin más, brindan la ilusión de inclusión como una versión depreciada de la verdadera participación educativa.

Seguidamente, se presentarán algunos programas públicos implementados entre el período 2000 y 2015 en algunos países de América Latina, que han tenido como principal meta la mejora del nivel educativo y de las condiciones de participación laboral de los jóvenes. Con el mismo énfasis, algunos de estas inciativas buscaron ampliar el grado de responsabilidad de los ciudadanos en torno a los beneficios obtenidos, de tal modo se persiguió ampliar la toma de conciencia acerca de la contraprestación de la ayuda estatal para sostener a largo plazo algunos programas ofrecidos desde el Estado. 


\section{Cuadro $\mathbf{N}^{0} 2^{2}$ :}

\section{Trece países de América Latina y el Caribe: Programas de transferencias condicionadas que consideran a las y los jóvenes como destinatarios}

\begin{tabular}{|c|c|c|c|}
\hline \multirow[t]{4}{*}{ Argentina } & Protección de ingresos & $\begin{array}{l}\text { Asignación Universal por } \\
\text { Hijo para } \\
\text { Protección Social }\end{array}$ & $\begin{array}{l}\text { Familias con jefes o jefas de } \\
\text { hogar desocupados o que se } \\
\text { desempeñen en } \\
\text { la economía informal, con } \\
\text { hijos e hijas menores de } 18 \\
\text { años }\end{array}$ \\
\hline & Protección de ingresos & $\begin{array}{l}\text { Familias por la Inclusión } \\
\text { Social }\end{array}$ & $\begin{array}{l}\text { Familias en riesgo social con } \\
\text { hijos e hijas menores de } 19 \\
\text { años }\end{array}$ \\
\hline & $\begin{array}{l}\text { Conclusión / } \\
\text { continuación de Estudios }\end{array}$ & $\begin{array}{l}\text { Programa Ciudadanía } \\
\text { Porteña }\end{array}$ & $\begin{array}{l}\text { Familias con hijos e hijas de } \\
18 \text { a } 29 \text { años }\end{array}$ \\
\hline & Protección de ingresos & $\begin{array}{l}\text { Jefes y Jefas de Hogar } \\
\text { Desocupados }\end{array}$ & $\begin{array}{l}\text { Familias con jefes o jefas de } \\
\text { hogar desempleados e hijos } \\
\text { e hijas menores } \\
\text { de } 18 \text { años }\end{array}$ \\
\hline $\begin{array}{l}\text { Bolivia } \\
\text { (Estado } \\
\text { Plurinacional } \\
\text { de) }\end{array}$ & $\begin{array}{l}\text { Conclusión / } \\
\text { continuación de } \\
\text { estudios }\end{array}$ & Bono Juancito Pinto & $\begin{array}{l}\text { Menores de } 18 \text { años que } \\
\text { asisten a escuelas públicas } \\
\text { de educación formal, juvenil } \\
\text { alternativa o especial }\end{array}$ \\
\hline Brasil & Protección de ingresos & $\begin{array}{l}\text { Bolsa Família - Beneficio } \\
\text { variable ligado al } \\
\text { adolescente }\end{array}$ & $\begin{array}{l}\text { Familias vulnerables con } \\
\text { hijos e hijas de } 16 \text { a } 17 \text { años }\end{array}$ \\
\hline \multirow[t]{2}{*}{ Chile } & Protección de ingresos & $\begin{array}{l}\text { Subsidio Único Familiar } \\
\text { (SUF) }\end{array}$ & $\begin{array}{l}\text { Hijos e hijas menores de } 18 \\
\text { años }\end{array}$ \\
\hline & $\begin{array}{l}\text { Conclusión / } \\
\text { continuación de estudios }\end{array}$ & $\begin{array}{l}\text { Asignación social - } \\
\text { Asignación por Matrícula y } \\
\text { Asistencia }\end{array}$ & Hijos e hijas de 6 a 18 años \\
\hline Colombia & $\begin{array}{l}\text { Conclusión / } \\
\text { continuación de estudios }\end{array}$ & $\begin{array}{l}\text { Subsidios Condicionados a } \\
\text { la Asistencia Escolar }\end{array}$ & $\begin{array}{l}\text { Hijos e hijas menores de } 19 \\
\text { años que cursan entre } 6^{\circ} \text { y } \\
11^{\circ} \text { grado (subsidio } \\
\text { educativo) e hijos e hijas de } \\
14 \text { a } 19 \text { años que cursan } \\
\text { entre } 9^{\circ} \text { y } 11^{\circ} \text { grado, y que } \\
\text { habitan a más de } 2 \mathrm{Km} \text {. del } \\
\text { centro escolar (subsidio de } \\
\text { transporte). }\end{array}$ \\
\hline Costa Rica & $\begin{array}{l}\text { Conclusión / } \\
\text { continuación de estudios }\end{array}$ & Avancemos & $\begin{array}{l}\text { Hijos e hijas de } 12 \text { a } 25 \text { años } \\
\text { que cursan secundaria en } \\
\text { establecimientos públicos }\end{array}$ \\
\hline Honduras & $\begin{array}{l}\text { Conclusión / } \\
\text { continuación de estudios }\end{array}$ & $\begin{array}{l}\text { Bono } 10.000 \text { - bono } \\
\text { educación }\end{array}$ & $\begin{array}{l}\text { Hijos e hijas de } 6 \text { a } 18 \text { años } \\
\text { matriculados en el sistema } \\
\text { público }\end{array}$ \\
\hline Jamaica & $\begin{array}{l}\text { Conclusión / } \\
\text { continuación de estudios }\end{array}$ & $\begin{array}{l}\text { Programa de avance } \\
\text { mediante }\end{array}$ & Niños y niñas de 6 a 17 años \\
\hline
\end{tabular}




\begin{tabular}{|c|c|c|c|}
\hline & & $\begin{array}{l}\text { la salud y la educación } \\
\text { (PATH) - Education grant }\end{array}$ & \\
\hline & $\begin{array}{l}\text { Conclusión / } \\
\text { continuación de estudios }\end{array}$ & $\begin{array}{l}\text { Programa de avance } \\
\text { mediante la salud y la } \\
\text { educación (PATH) - Bonus }\end{array}$ & $\begin{array}{l}\text { Hijos e hijas que terminan la } \\
\text { educación secundaria y } \\
\text { prosiguen a la educación } \\
\text { superior }\end{array}$ \\
\hline México & $\begin{array}{l}\text { Conclusión / } \\
\text { continuación de estudios }\end{array}$ & Oportunidades & $\begin{array}{l}\text { Hijos e hijas que cursan } \\
\text { educación primaria, } \\
\text { secundaria o media superior } \\
\text { (apoyo educativo) y } \\
\text { estudiantes entre } 3^{\circ} \text { de } \\
\text { secundaria y } 4^{\circ} \text { de } \\
\text { bachillerato (Jóvenes con } \\
\text { Oportunidades) }\end{array}$ \\
\hline Nicaragua & Formación ocupacional & $\begin{array}{l}\text { Red de Protección Social } \\
\text { (RPS) - Bono formación } \\
\text { ocupacional }\end{array}$ & $\begin{array}{l}\text { Jóvenes de } 14 \text { a } 25 \text { años con } \\
\text { primaria completa }\end{array}$ \\
\hline Paraguay & $\begin{array}{l}\text { Conclusión / } \\
\text { continuación de estudios } \\
\text { y apoyo en salud }\end{array}$ & Tekoporâ & $\begin{array}{l}\text { Hijos e hijas de hasta } 18 \\
\text { años }\end{array}$ \\
\hline $\begin{array}{l}\text { República } \\
\text { Dominicana }\end{array}$ & $\begin{array}{l}\text { Conclusión / } \\
\text { continuación de estudios }\end{array}$ & $\begin{array}{l}\text { Solidaridad - Incentivo a la } \\
\text { asistencia escolar (ILAE) }\end{array}$ & $\begin{array}{l}\text { Hijos o hijas de } 4 \text { a } 21 \text { años } \\
\text { matriculados en la educación } \\
\text { pública }\end{array}$ \\
\hline Uruguay & Protección de ingresos & Asignaciones Familiares & $\begin{array}{l}\text { Hijos e hijas menores de } 18 \\
\text { años }\end{array}$ \\
\hline
\end{tabular}

La mayoría de estos programas de formación, en la práctica, dado el corto plazo estipulado para su implementación y extrema focalización en algunos casos han logrado un bajo impacto social. Así por ejemplo, los programas de formación y capacitación se caracterizaron prevalentemente por ofrecer trayectos formativos y curriculares desactualizados y poco atractivos para la mayoría de los jóvenes y que además, al ser percibidos como ofertas "especiales" destinadas a suplir carencias y debilidades (discriminación positiva), fueron una referencia de estigmatización y desvalorización social. A esto se agrega la disposición insuficiente de recursos técnicos, financieros y profesionales, lo cual ha obstaculizado la extensión de ofertas de formación potentes para los ciudadanos (GARCÍA HUIDOBRO, 2007).

Tomando como referencia las reformas educativas implementadas recientemente, se puede sostener que el objetivo primordial parece seguir apuntalando a remediar a corto plazo la dimensión de problemas estructurales como por ejemplo la segregación cultural, la discriminación social y la desigualdad económica todos ellos intrínsecos a los procesos de formación que restringen significativamente el aporte de las propuestas de formación y de las estrategias de compensación socioeducativas (APARICIO, 2014b). Es decir, de no proponerse acciones y políticas estructurales, la brecha que separa a las realidades económicas y grupos sociales heterogéneos, cualquier preconización discursiva que pretenda la reparación de la deuda social acumulada queda, desgraciadamente, exenta de toda viabilidad. 


\section{El universalismo curricular como mandato democratizante que homogeneiza.}

Más allá de las reformas implementadas la hegemonía de un currículum universal y coercitivo que impone "desde arriba" una propuesta democrática de formación homogénea, que amén de su intención política democrática y compensatoria del nuevo modelo educativo, ha tendido a cooptar los matices y las características de los diferentes contextos sociales, culturales e institucionales. Con ello, acaba por amedrentar la capacidad de gestión de las regiones federales para elaborar políticas descentralizadas y desarrollar modelos de formación más adaptados a los entornos locales.

En este contexto, la educación promueve una forma sutil de exclusión y negación cultural así, por ejemplo, cuando los alumnos y alumnas procedentes de grupos étnicos y culturales diferentes logran acceder al sistema de formación, en muchos casos se ven obligados a aprender contenidos curriculares ajenos y poco referenciados a sus entornos sociales de vida y demandas específicas (APARICIO, 2011). Recurrentemente no se suele buscar la articulación entre los aprendizajes y los referentes plurales de conocimiento sino que, más bien, se opta por imponer un modelo cultural y escolar dominante pautado para los sujetos que descuida - sutil o deliberadamente - la ponderación de los múltiples referentes sociales de vida y las prácticas de aprendizajes existentes y plurales.

Por otro lado, el acceso social diferenciado a los conocimientos y competencias de calidad se condice con el desgranamiento de las ofertas educativas que repercute negativamente en el desarrollo de las trayectorias educativas de los sujetos. En esta perspectiva, se requieren instituciones educativas más abiertas, dinámicas y compenetradas con la vida de las personas, su cotidianeidad, su cosmovisión y, obviamente, su horizonte nuevo de posibilidades. La apertura del espacio educativo podría aportar a la reorganización de los procesos y el desempeño de los actores vinculados a la formación y así propiciar una mejor adecuación de los procesos pedagógicos, la transposición de propuestas didácticas y la sistematización de los contenidos curriculares (POGGI, 2014).

Como ya fuera evidenciado en los recientes procesos de reforma pedagógica, sin una apertura y vinculación sinérgica de la educación con otros ámbitos estratégicos de la vida social, el incremento de la matrícula, la innovación tecnológica, la capacitación del personal docente y la retención escolar per se no resultan concluyentes para medir la efectividad de las políticas y los programas y menos aún para garantizar la transformación de estructuras y procesos intrínsecos al sistema educativo.

El carácter desfasado que reviste la oferta curricular (estandarizada y universalizante) y los dispositivos didácticos y metodológicos evidencia la escasa consideración que se tiene todavía sobre las múltiples demandas y los contextos de vida de los diferentes grupos socioculturales al momento de diseñar la agenda política educativa en América Latina (GENTILI, 2009). Por ende, el currículum, el rol de los profesores, las instituciones y la política educativa requieren ser revisados desde su capacidad para promover el desarrollo de competencias críticas en el ámbito de la cultura y de la vida social, enfatizando la necesidad de promover mayor igualdad en el conjunto de las relaciones sociales y educativas en, desde y más allá de la escuela.

La visibilización y atención de las demandas específicas correspondientes a las minorías étnico - culturales en América Latina, aún en nuestros días se sigue interpretando como la necesidad de remediar las carencias de los grupos excluidos y vulnerables, idea que se ampara en una visión negativa y negativizante del "otro distinto", que acaba por pronunciar la estigmatización social y cultural (SANTOS REGO, LORENZO MOLEDO \& APARICIO, 2010; Vila Merino \& Jiménez, 2010). Con este perfil ideológico, se continúa insistiendo en crear programas y proyectos especiales destinados a la integración de sujetos 
deficitarios y vulnerables, que sufren ante todo, su condición disminuida - deficitaria de ser "distintos y diversos", obviamente, dentro de un orden cultural y social desde donde se propaga el credo de la existencia de una cultura superior y más acabada y se cercena la posibilidad de avanzar en la construcción de una identidad más compleja y complementaria, que pondere y enriquezca en lugar de denigrar y amedrentar la diversidad subyacente (VILA MERINO, 2010).

El débil reconocimiento de la diversidad cultural como fundamento de una propuesta educativa crítica y pertinente constituye sólo "la punta de iceberg" de un problema de fondo basado en la desigualdad, en la segregación cultural y en las escasas oportunidades de inclusión que sufren los grupos minoritarios y otros sectores desaventajados. Irrumpir sobre el orden inmanente de la exclusión social significa plantar cara a la injusticia social, a la pobreza y a la desigualdad imperantes en América Latina y el Caribe, lo que en el fondo desmedra la posibilidad de construir un espacio de convivencia a través de la vinculación de la diferencia, el respeto a la diversidad y el conocimiento mutuo como punto de partida para la construcción de una sociedad plural e intercultural (APARICIO, 2015; SOETERIK, 2010; UNESCO, 2010).

A través de la extensión del sistema educativo y sus modelos didácticos, el currículum y los perfiles profesionales se ha contribuido a propagar los valores y la cosmovisión referidos a una cultura única y mayoritaria que, indudablemente, desmedra la posibilidad de incluir a la diversidad, vale decir a los otros distintos pero iguales, que encarnan la multiplicidad de voces particulares e identidades plurales que al ser adaptadas a través del filtro de la aculturación son subyugadas. Y por ende, se lesiona el principio ético universal del bien común, pues lo general y lo compartido en este caso, actúan coercitivamente excluyendo lo particular y negando lo distinto y lo plural en nombre de una supuesta igualdad que no repara ni en la desigualdad socioeconómica ni en la diversidad cultural que condicionan la disposición de las personas en los múltiples ámbitos de la vida social (PNUD, 2009).

Las nuevas políticas públicas desarrolladas en la región adolecen de limitaciones para ampliar las posibilidades de intervención de las minorías étnico - culturales (comunidades indígenas y grupos afrodescendientes fundamentalmente) en las instancias en donde se discuten y elaboran los programas políticos. Por este motivo, la necesidad de elaborar mecanismos y oportunidades de participación e integración social para y con los diferentes grupos étnico - culturales se inscribe en uno de los retos más sobresalientes a atender y que ha propulsado la reciente reforma de políticas públicas en áreas estratégicas del desarrollo así como también la elaboración de programas focalizados a las demandas concretas y la búsqueda de nexos conciliadores de trabajo entre el Estado, el sector privado, las organizaciones civiles y las Agencias de Cooperación para el Desarrollo nacionales e internacionales.

Especialmente en el caso de los grupos étnico - culturales minoritarios (indígenas y afrodescendientes) la segregación educativa impacta con mayor determinación, prolongando la brecha social imperante. Al respecto, la CEPAL \& UNFPA (2011:52) sostiene que "en promedio, el $64,5 \%$ de las y los jóvenes de entre 20 y 24 años que pertenecen a pueblos indígenas o son afrodescendientes han concluido el nivel correspondiente a la baja secundaria, es decir, una proporción menor en 15 puntos porcentuales a la de las y los jóvenes que no son ni indígenas ni afrodescendientes $(79,7 \%)$.

A continuación y como se podrá apreciar estadísticamente en el Cuadro $\mathrm{N}^{\circ} 3$, los grupos étnico - culturales minoritarios son quienes más quedan restringidos de poder participar de las oportunidades educativas, lo que a su vez explica la propensión a la reproducción de las desigualdades sociales y económicas. 
Concremente la brecha de desiguladad se plantea en el acesso pero sobre todo en la conclusión de la educación secundaria alta (que contempla los últimos años previo a la conclusión del ciclo), así por ejemplo para el grupo de personas ubicadas entre 20 a 29 años de edad, sólo un 43,9\% de las y los jóvenes de procedencia indígena y afrodescendiente logra este objetivo, mientras que el resto de los jóvenes lo realizan en un $61 \%$. Este hecho revela la presencia de factor significativo de desaventajamiento que comprueba que ser indígena y/o afrodecescendiente sigue apareciendo como una causa de restricción cultural y desigualdad socioeconómica.

\section{Cuadro $\mathbf{N}^{0} 3^{3}$ \\ Nueve países de América Latina: \\ Tasas netas de asistencia a educación primaria y secundaria y conclusión del ciclo primario entre jóvenes de 15 a 19 años y del secundario entre jóvenes de 20 a 24 años, según área geográfica de residencia y origen étnico, 2008 (en porcentajes)}

\begin{tabular}{|c|c|c|c|c|c|c|c|c|}
\hline \multirow[t]{3}{*}{ País } & \multirow{2}{*}{\multicolumn{2}{|c|}{$\begin{array}{c}\text { Tasa neta de asistencia a } \\
\text { educación primaria } \\
\text { Total nacional }\end{array}$}} & \multicolumn{4}{|c|}{ Conclusión de la ensañanza primaria } & \multirow{2}{*}{\multicolumn{2}{|c|}{$\begin{array}{c}\text { Tasa neta de asistencia a } \\
\text { educación primaria } \\
\text { Total nacional }\end{array}$}} \\
\hline & & & \multicolumn{2}{|c|}{ Total nacional } & \multicolumn{2}{|c|}{ Zonas rurales } & & \\
\hline & $\begin{array}{c}\text { Indígena o } \\
\text { afrodescendente }\end{array}$ & $\begin{array}{l}\text { No indígena ni } \\
\text { afrodescendente }\end{array}$ & $\begin{array}{c}\text { Indígena o } \\
\text { afrodescendente }\end{array}$ & $\begin{array}{l}\text { No indígena ni } \\
\text { afrodescendente }\end{array}$ & $\begin{array}{c}\text { Indígena o } \\
\text { afrodescendente }\end{array}$ & $\begin{array}{l}\text { No indígena ni } \\
\text { afrodescendente }\end{array}$ & $\begin{array}{c}\text { Indígena o } \\
\text { afrodescendente }\end{array}$ & $\begin{array}{l}\text { No indígena ni } \\
\text { afrodescendente }\end{array}$ \\
\hline \multicolumn{9}{|l|}{$\begin{array}{l}\text { Bolívia } \\
\text { (Estado }\end{array}$} \\
\hline $\begin{array}{l}\text { Plurinacional } \\
\text { de) (2007) }\end{array}$ & --- & --- & 90 & 95 & 86 & 90 & 90 & 94 \\
\hline Brasil (2008) & 98 & 99 & 93 & 95 & 83 & 89 & 91 & 93 \\
\hline Chile (2006) & 98 & 99 & 98 & 99 & 97 & 98 & 94 & 95 \\
\hline \multicolumn{9}{|l|}{ (2008) } \\
\hline $\begin{array}{l}\text { El Salvador } \\
\text { (2004) }\end{array}$ & 92 & 92 & 74 & 78 & 63 & 65 & 83 & 79 \\
\hline $\begin{array}{l}\text { Guatemala } \\
(2006)\end{array}$ & 86 & 91 & 49 & 71 & 40 & 58 & 61 & 75 \\
\hline $\begin{array}{l}\text { Nicaragua } \\
(2005)\end{array}$ & 85 & 81 & 58 & 71 & 46 & 54 & 86 & 84 \\
\hline $\begin{array}{l}\text { Panamá } \\
\text { (2008) }\end{array}$ & 98 & 99 & 73 & 97 & 73 & 93 & 74 & 89 \\
\hline $\begin{array}{l}\text { Paraguay } \\
(2008)\end{array}$ & 96 & 98 & 83 & 94 & 82 & 87 & 71 & 92 \\
\hline Total países & 93 & 97 & 82 & 93 & 70 & 84 & 85 & 92 \\
\hline \multirow[t]{3}{*}{ País } & \multicolumn{4}{|c|}{ Conclusión de la baja secundaria } & \multicolumn{4}{|c|}{ Conclusión de la baja secundaria } \\
\hline & \multicolumn{2}{|c|}{ Total nacional } & \multicolumn{2}{|c|}{ Zonas rurales } & \multicolumn{2}{|c|}{ Total nacional } & \multicolumn{2}{|c|}{ Zonas rurales } \\
\hline & $\begin{array}{c}\text { Indígena o } \\
\text { afrodescendente }\end{array}$ & $\begin{array}{l}\text { No indígena ni } \\
\text { afrodescendente }\end{array}$ & $\begin{array}{c}\text { Indígena o } \\
\text { afrodescendente }\end{array}$ & $\begin{array}{l}\text { No indígena ni } \\
\text { afrodescendente }\end{array}$ & $\begin{array}{c}\text { Indígena o } \\
\text { afrodescendente }\end{array}$ & $\begin{array}{l}\text { No indígena ni } \\
\text { afrodescendente }\end{array}$ & $\begin{array}{c}\text { Indígena o } \\
\text { afrodescendente }\end{array}$ & $\begin{array}{l}\text { No indígena ni } \\
\text { afrodescendente }\end{array}$ \\
\hline \multicolumn{9}{|l|}{$\begin{array}{l}\text { Bolívia } \\
\text { (Estado }\end{array}$} \\
\hline $\begin{array}{l}\text { Plurinacional } \\
\text { de) (2007) }\end{array}$ & 76 & 88 & 62 & 68 & 55 & 71 & 38 & 44 \\
\hline Brasil (2008) & 74 & 78 & 49 & 53 & 47 & 56 & 24 & 27 \\
\hline Chile (2006) & 94 & 96 & 84 & 89 & 65 & 81 & 50 & 63 \\
\hline $\begin{array}{l}\text { Ecuador } \\
\text { (2008) }\end{array}$ & 47 & 73 & 38 & 48 & 31 & 59 & 23 & 33 \\
\hline $\begin{array}{l}\text { El Salvador } \\
\text { (2004) }\end{array}$ & 60 & 57 & 41 & 35 & 37 & 56 & 17 & 17 \\
\hline $\begin{array}{l}\text { Guatemala } \\
\text { (2006) }\end{array}$ & 19 & 44 & 12 & 20 & 13 & 33 & 7 & 12 \\
\hline $\begin{array}{l}\text { Nicaragua } \\
(2005)\end{array}$ & 34 & 44 & 11 & 21 & 21 & 32 & 5 & 13 \\
\hline $\begin{array}{l}\text { Panamá } \\
\text { (2008) }\end{array}$ & 36 & 79 & 36 & 58 & 12 & 60 & 12 & 40 \\
\hline $\begin{array}{l}\text { Paraguay } \\
(2008)\end{array}$ & 45 & 80 & 40 & 54 & 25 & 62 & 21 & 36 \\
\hline Total países & 62 & 77 & 38 & 49 & 40 & 56 & 20 & 28 \\
\hline
\end{tabular}




\section{Desigualdad educativa y diversidad cultural: tensiones y desafíos}

La participación desigual en el sistema educativo repercute ulteriormente en una distribución también desigual de los puestos de empleo, los salarios, las condiciones de bienestar, las oportunidades laborales y el acceso a todos los servicios sociales básicos (CEPAL, 2013).

La falta de ofertas de empleo y posibilidades genuinas de inclusión está constreñida a la carencia de oportunidades educativas formales y no-formales de los jóvenes, fenómeno que compromete las expectativas de superación de la condición social vivida y coadyuva a relativizar la contribución de los programas sociales y el conjunto de políticas públicas destinadas a la atención de las demandas específicas (CEDLAS, 2013).

$\mathrm{Al}$ respecto también es importante recalcar que el acceso a la educación en sociedades autoreconocidas como pluriétnicas y culturales -exceptuando el caso paradigmático de Bolivia y Ecuador- se sigue pensando desde el parámetro cultural uniformante, lo que en términos generales contribuye a seguir oprimiendo no solo el cultivo de la diversidad sino, sobre todo, el avance hacia un desarrollo más integrador y cohesionante del pensamiento y la alteridad no a pesar de sino a partir de la pluralidad. Como un aspecto nodal de la heterogeneidad social y la pluralidad étnica - cultural de América Latina y el Caribe se debe subrayar que gran parte de las comunidades indígenas y afrodescentientes poseen idiomas propios arraigados a tradiciones, sistemas de valores, modelos económicos y principios de convivencia con el medio físico, histórico y natural, que ante el avance de las políticas de homogeneización cultural, han sido el blanco de la negación cultural.

La homogeneización cultural antes aludida se produce en y a través del sistema educativo. Al respecto recientes estudios elaborados en América Latina y en el Caribe advierten sobre la impronta homogeneizante de la cultura escolar en contextos plurales y heterogéneos (ver Grosfogel, 2007, 2008; Fornet - Betancourt, 2003) demuestran que el "colonialismo cultural" sigue obrando como tamiz en la construcción identitaria y la representación ideológica que las sociedades esgrimen en torno al "otro distinto" y que además se extiende también a los valores de lo bueno, lo desable y lo admitido en términos axiológicos, sociales y culturales. Esta categorización valora y anticipa el sentido de la identidad propia y ajena, definiendo los atributos de la soberanía cultural y el derecho de vivir plenamente la facultad de autodeterminación, todo esto bajo el primado de una cultura mayoritaria y una sociedad cohesionada en valores comunes y homogeneizates (KREHOFF, 2008).

La tensión plenteada entre las minorías y las mayorías culturales también se instala dentro de la arena educativa, donde no sólo conviven y se (des)encuentran distintas culturas, identidades, cosmovisiones y subjetividades sino en donde también, se socializan conocimientos, competencias y disposiciones avaladas en un currículum que, a su vez, asume el mandato histórico de acumular, organizar y garantizar monópolicamente la transmisión intergeneracional de un determinado conjunto de saberes socialmente legítimos, reconocidos y válidos para todos.

El currículum como elemento neurálgico de la cultura y la funcionalidad escolar trasfiere una idea del mundo y del hombre, una definición de cultura, una axiología y patrones de convivencia éticos fundamentales que, en el caso de América Latina, todavía plantea serias limitaciones al momento de reconocer y abarcar la amplia diversidad y contrastes sociales, culturales e idionsincrásicos subyacentes, valga la aclaración, que escapan y resisten a la conducción política hegemónica, los cánones axiológicos monopólicos inherentes a las instituciones y la venia de los discursos de poder dominantes. ${ }^{4}$

En la región se observa que el porcentaje más alto de la población indígena de 15 - 
29 años posee una escolaridad total entre 0 a 6 años, a diferencia del resto de los jóvenes, que acumulan 7 años o más. Así por ejemplo se destaca la situación de Paraguay en donde un $63,7 \%$ de los jóvenes indígenas registra tan solo una escolaridad de 0 a 3 años y en Guatemala los jóvenes indígenas que alcanzan este mínimo umbral de escolaridad representa el 55,3\%. A modo de contraste se podría mencionar el caso de Argentina o Chile, donde alrededor del $85 \%$ de los jóvenes indígenas logra 7 años de escolaridad o más. Por otro lado, en un nivel más moderado se encuentran países como Ecuador, Costa Rica y Honduras donde la mayoría de los jóvenes indígenas logra acumular entre 4 a 6 años de escolaridad (DEL POPOLO, LÓPEZ Y ACUÑA, 2009).

Este panorama revela que al día de hoy la gran mayoría de las nuevas generaciones de indígenas solo acceden y con dificultad al nivel educativo primario y así suelen quedar atrapados en los primeros años, afectados por el influjo de problemas como la repitencia, la segregación cultural, el desgramiento de los contenidos curriculares y la falta de implicancia biográfica y social de las ofertas de formación.

La no implicación de las minorías étnico - culturales en el diseño de los procesos de enseñanza y aprendizaje (invisibilización) repercuten en la extensión de comportamientos y actitudes insolidarias y excluyentes que encubren y potencian conductas proclives a la intolerancia, el rechazo racial y la negación de la alteridad (KREHOFF, 2008; CEPAL, 2012; FORNET - BETANCOURT, 2003).

El debilitamiento de la cohesión social, derivada de la primacía de los intereses particulares que resisten desde el rechazo y la negación intercultural el peligro de una interpelación amenazante y/o incomoda que pudiese poner en cuestión el goce de derechos y privilegios, aunque estos peligros, sean más un constructo simbólico carente de fundamentación empírica.

La parcialidad y la diferencia anteponen la preservación de los derechos y los privilegios personales al cumplimiento del derecho de todos, desmedrando el carácter democrático de la educación pública y las posibilidades incluyentes que otorga la participación a una oferta educativa de calidad. De este modo, la no aceptación de "el diferente, el distinto, el otro" pronuncia la segregación cultural en el marco de una política educativa que si bien en términos formales se pronuncia a favor del respeto de los valores de la democracia y el respeto por la diversidad, en la práctica, dichas pretensiones se contradicen y quedan entrapadas en atisbos de buena voluntad por cierto inviables o utópicos (GROSFOGUEL, 2008).

El problema de la invisibilización política de la diversidad cultural va más allá de la falta de reconocimiento de las nuevas identidades sociales y culturales, y de la escasa flexibilidad inherente a los modelos pedagógicos y a la dimensión curricular de la tarea formativa. El problema reside en el sentido mismo en cómo se piensa la política educativa desde los cánones fundantes de la cohesión social y su compromiso inalienable con el desarrollo de una sociedad intercultural y plural y el sustento de un proyecto social democrático vinculante, capaz de aprehender y objetivar las múltiples demandas e intereses existentes dentro de las instituciones educativas (SANTOS REGO \& APARICIO, 2014; SANTOS REGO \& LORENZO MOLEDO, 2012).

En el ámbito educativo el problema de construir una mayor inclusión social apoyada en la ampliación de la estructura de oportunidades, se debe por un lado, a la falta de adecuación de los dispositivos políticos e institucionales a la diversidad cultural, subjetiva y socioeconómica y por otro lado, al distanciamiento imperante entre las ofertas políticas y las demandas reales de los grupos sociales, aspectos que tendieron a agravar el vaciamiento de sentido de la propuesta pedagógica y la desigualdad educativa y social subyacente (TIRAMONTi, 2012). 
La asimetría planteada entre los objetivos y las expectativas de la escuela y del sistema educativo y las posibilidades de logro y/o éxito académico de los grupos juveniles más vulnerables refuerza desde la convicción de que el fracaso y el bajo desempeño académico de estos actores se debe a déficits de índole motivacional y a la falta de compromiso personal y el esfuerzo familiar (APARICIO, 2013; DUBET, 2011).

A nuestro juicio, el modo en cómo se concibe y pone en ejecución una política determinada no se puede disociar de la forma en cómo son visualizados los actores referenciales - en esta caso los jóvenes- y sus contextos socioeconómicos de vida, universos simbólicos, enclaves sociohistóricos, subjetividades e identidades culturales. Así, la forma en cómo se percibe el universo social a donde se circunscribe la propuesta educativa resulta determinante para dirimir los criterios políticos, epistemológicos e institucionales a la hora de dimensionar las potencialidades y las limitaciones reales prevalecientes en el contexto de formación.

De especial modo, los jóvenes procedentes de sectores populares tienen mayores dificultades para acceder a los servicios sociales y los bienes materiales mínimos para poder participar de la vida social, en este sentido, estos grupos experimentan una doble marginación, a saber, en primer lugar por ser "jóvenes" -que desde la visión estigmatizadora y adultocéntrica aún prevaleciente en la sociedad se sigue conciendo a este grupo como un grupo homogéneo desinteresado, violento y pasivo, y en segundo lugar, este grupo sufre la segregación por su condición de "pobre y vulnerable".

En contextos de pobreza, la falta de oportunidades conlleva a la naturalizacion de la carencia, la indefensión y la restricción como elementos inherentes a la vida simbólica y material de las personas. Así la ausencia de posibilidades -reales y potenciales- de inclusión y permanencia en los diferentes ámbitos de la vida social, laboral, institucional, educativa, familiar, política, ciudadana, recreativa y asociativa repercuten en la dimensión subjetiva y la disposición social de las personas al momento de pelear el ingreso en los diferentes ámbitos de la vida social.

En una reciente encuesta realizada a jóvenes en América Latina y el Caribe por parte de la OIJ et al. (2012:47) se advierte que la valoración de la gran mayoría de los jóvenes que realizan a torno a la educación es fuertemente negativa, pues se afirma que la calidad del servicio recibido es "regular", vale decir que es incapaz de satisfacer las demandas objetivas y de proveer competencias y herramientas cognitivas y sociales apropiadas para afrontar los desafíos futuros.

La concatenación planteada entre los hogares de origen y el tipo de ofertas educativas subraya la importancia de insistir en la búsqueda de mecanismos y estrategias políticas que favorezcan la superación de las causas de (des)igualación social. Asimismo, representa un objetivo prioritario a atender desde las agendas políticas. En el ámbito educativo concretamente, resulta imperioso propiciar una base de acuerdo con vasta capacidad de extensión y cohesión social, que articule intereses polivalentes de los jóvenes y genere por consiguiente una posición política coherente y clara, sensible a la diversidad que la sostiene y provista de la capacidad de aportar al desarrollo de políticas y acciones destinadas a ampliar las oportunidades de participación social (URQUIOLA, 2006; APARICIO, 2012).

$\mathrm{Al}$ día de hoy, detentar una determinada credencial educativa ya no representa una garantía de ascenso social y mucho menos de conservación del status logrado, empero a esto, el acceso a la escolaridad en todos sus niveles sigue mejorando las posibilidades de inclusión social puesto que ella sigue proveyendo herramientas cognitivas, sociales e intelectuales para generar estrategias de superación frente a conflictos, gestionar las propias decisiones y elaborar de forma autónoma los proyectos de vida.

El desmembramiento de las garantías añadidas a la participación educativa tiende a 
exacerbarse en un clima de inseguridad y crisis que, agrava la situación de vida de las nuevas generaciones y amedrenta sus expectativas y proyectos futuros.

Si bien la cobertura educativa se ha propagado a nivel regional esto no ha sopesado las todavía altas tasas de deserción y la segmentación de los sistemas educativos que engendran consigo espacios y procesos paralelos de formación, que repercuten en la diferenciación de la calidad en torno a la organización del servicio a nivel de las instituciones, los profesionales, la oferta curricular, las metodologías pedagógicas, los modelos y los recursos didácticos, la disposición tecnológica y la capacidad de desarrollar y adquirir insumos técnicos propios.

\section{Educación, jóvenes e inclusión social}

Las nuevas generaciones están expuestas a cambios vertiginosos y a múltiples paradojas y contradicciones que reseñan su tiempo histórico y moldean sus itinerarios sociales y biográficos en las múltiples esferas de la vida educativa, laboral, civil y cultural.

En un clima social urdido por la desigualdad y la inseguridad, los jóvenes -dotados de creatividad, valor y esfuerzo- buscan abrirse paso a la vida adulta asumiendo retos y desarrollando estrategias para sobreponerse a los desafíos que impone la vulnerabilidad económica, la falta de modelos políticos y dispositivos institucionales sólidos y la fragmentación del espacio social que ahora se infringen en condiciones estructurales de la vida social (DURU -BELLAT \& VERLEY, 2009).

Paradójicamente, los jóvenes de hoy, y en comparación a la generación de sus padres y sus abuelos, son más flexibles, dinámicos y creativos, demuestran una mayor adhesión a valores como la tolerancia, la empatía y el asociacionismo. Así también, están más informados y familiarizados con las nuevas tecnologías, las redes comunicativas virtuales y la sociedad de la información; y además cuentan con niveles elevados de cualificación, instrucción escolar y capital cultural (SITEAL, 2006).

Empero a estos méritos intrínsecos a la presente generación, los jóvenes siguen estando expuestos al desempleo, a la devaluación de sus credenciales educativas -al momento de postular el ingreso laboral o la continuidad de sus estudios - y a la informalidad laboral. Con igual énfasis, los jóvenes aparecen como el sector también más vulnerable a la pobreza, la segregación económica, la desigualdad, la invisibilización política, la negación cultural e identitaria, la fragmentación y la exclusión social (HOPENHAYN, 2013; WELLER \& ROETHLISBERGERG, 2011).

En referencia a diferentes estudios elaborados sobre el estado de la educación en América Latina se puede sostener que áun no está asegurado para todos los jóvenes el acceso a un sistema educativo de calidad, la participación en un mercado de trabajo productivo y el goce derechos y beneficios sociales elementales. La introducción de programas y políticas de apoyo en ámbitos estratégicos del desarrollo en el ámbito de juventud no ha podido refrendar el peso y la influencia que tienen la vulnerabilidad y los contextos de pobreza (TORRES, 2008; DRIKSON, 2008). En consecuencia, la posibilidad de participar a largo plazo y de forma irrestricta de los beneficios de la vida social e institucional se haya transformado para muchos, en un privilegio poco asequible al común de los ciudadanos después de que constituyera durante gran parte del siglo XX un axioma fundamental de la inclusión democrática y la cohesión social desde una perspectiva universal (APARICIO, 2008).

Actualmente, las nuevas y las viejas generaciones están siendo interpeladas por una difícil coyuntura histórica plagada de inflexiones y brechas que han provocado que los 
procesos de inclusión social tiendan a desmembrarse en una metamorfosis progresiva y global que pone "en jaque" los fundamentos de la vida social a saber: la legitimidad de los discursos políticos y sociales cohesionantes, la importancia de los derechos sociales, la sostenibilidad de los pactos colectivos, las garantías institucionales y las normas de convivencia social, la importancia de la moratoria intergeneracional en términos educativos, culturales y familiares, el valor de la idiosincrasia y del bagaje cultural detentado, la condición de ciudadanía y el significado de lo público y lo político.

En medio de un escenario plagado de restricciones y oportunidades en términos políticos todos los gobiernos de la región coinciden en que resulta primordial fortalecer la participación en el ámbito educativo y laboral para conquistar mayores niveles de inclusión social.

Empero a este consenso prevalesciente en la región, sigue resultando alarmante la cantidad de jóvenes que ni estudian ni trabajan, que valga la redundancia, acumulan consigo desventajas sociales que suelen derivar ulteriormente en una mayor exclusión social. Del mismo modo, resulta también problemático que más allá de la favorable coyuntura económica y productiva experimentada en la región en el período comprendido entre 2007 - 2011 potenciada por el extractivismo económico no se haya aprovechado adecuadamente para el diseño de políticas estructurales, continuas y singérgicas. Sin bien, se han organizado importantes fondos públicos para la activación de programas y políticas de fomento al trabajo, no se ha podido reducir considerablemente la cantidad de personas que seguían permaneciendo privadas del acceso a la educación y al empleo digno.

Como bien se puede evidenciar en el Cuadro $\mathrm{N} 4$, la gran mayoría de jóvenes que carecen de perspectivas educativas y laborales están circunscriptas en países afectados por el antagonismo social, la desigualdad económica, la inseguridad, la violencia colectiva y la baja efectividad de las acciones públicas e institucionales compensatorias. En este sentido, se puede considerar algunos países de América Central, donde el promedio de vida de los jóvenes entre los sectores populares, pobres y sumidos en el flagelo de la violencia no excede los 29 años de edad (REGUILLO, 2012; CEPAL \& UNFPA, 2012; OIJ et al., 2012).

\section{Cuadro No $4^{5}$ : \\ Deiciocho países de América Latina: jóvenes entre 15 y 29 años que no estudian ni trabajan remuneradamente, por grupo de edad, alrededor de 2009} (En porcentajes)

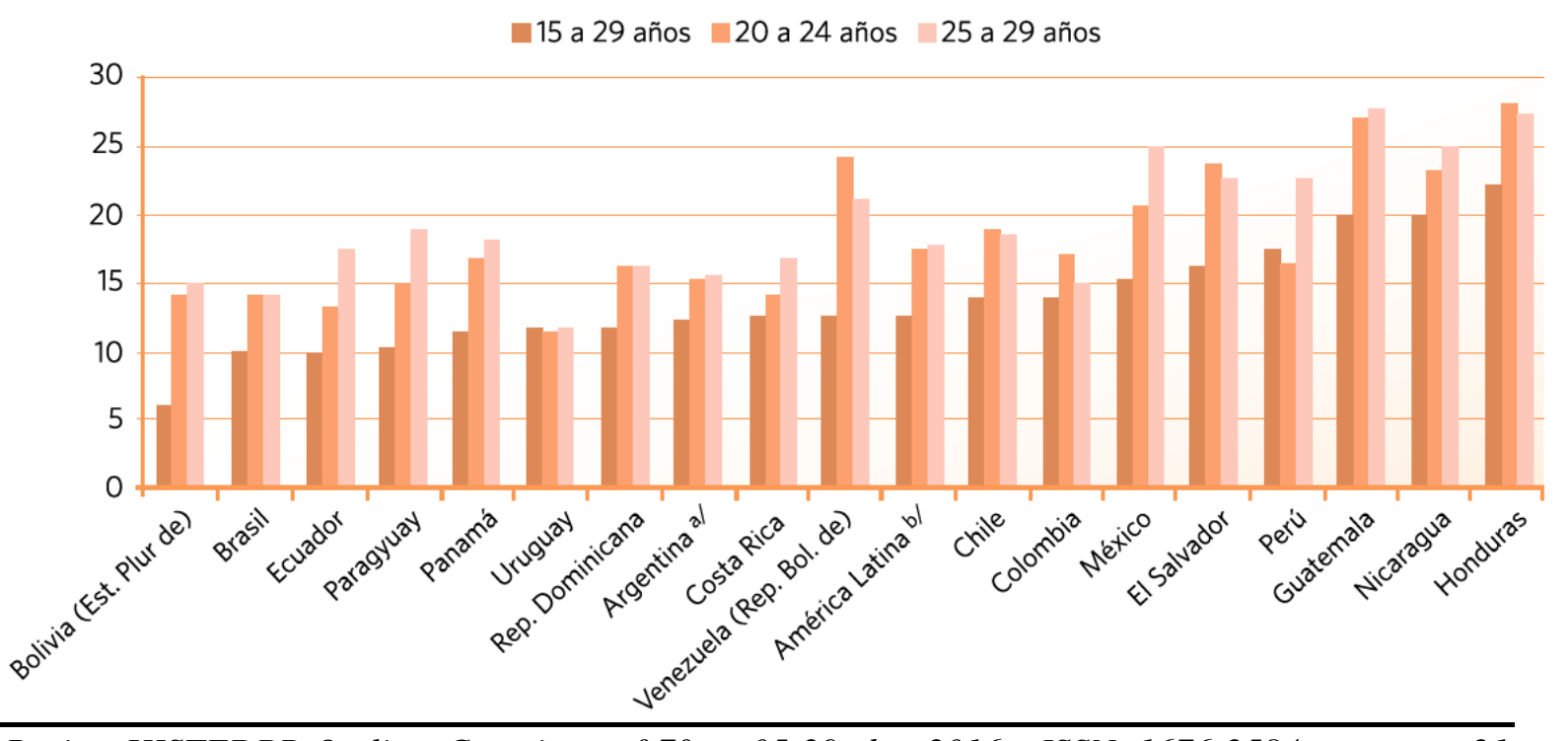

Revista HISTEDBR On-line, Campinas, $n^{o}$ 70, p. 05-29, dez. 2016-ISSN: 1676-2584 
En este escenario, los jóvenes asumen con mucha dificultad el relevo intergeneracional de roles, funciones y mandatos, pues las vías tradicionales de inclusión y participación social al sufrir el impacto de los cambios antes aludidos, pierden fuerza (Aparicio, 2015). En consecuencia, la exacerbación de la indefensión expone uno de los condicionantes más exponenciales que reseñan los procesos de socialización y partipación de los jóvenes que buscan - con serias restricciones- abordar los desafíos y las exigencias de mercado de trabajo cada vez más inestable, competitivo y cambiante.

\section{Propuestas y conclusiones}

En América Latina los avances en materia de democratización de la oferta educativa ${ }^{6}$ ha sido posible gracias a la creación de un mayor número de centros escolares primarios, secundarios y terciarios, al incremento de personal docente y otros técnicos especializados, gabinetes psicopedagógicos, el aumento de la matrícula en todos los niveles del sistema obtenido gracias a la introducción de programas de becas, ayudas y créditos públicos, privados y concertados que favorecieron el acceso educativo para muchos grupos sociales que estuvieron históricamente rezagados.

Del mismo modo, y como un efecto derivado de la masificación de las credenciales educativas, se constata que el nivel de formación adquirido no siempre es compatible con la calidad de los certificados obtenidos. La proyección como impacto directo del capital educativo en cada uno de los trayectorias sociales y laborales, se diferencia. Con ello, la calidad de la oferta y el efecto cualificante en los sujetos relativiza el impacto favorable de las reformas educativas y las nuevas inversiones públicas acometidas, que han hecho ahínco en abrir las puertas de las instituciones escolares como vía predilecta de democratización y compensación de las desigualdades.

Más allá de la ampliación de las oportunidades educativas en todos los niveles del sistema de formación, esto no se ha traducido en la compensación de las desigualdades sociales que continúan diferenciando la distribución de los bienes culturales y la participación en los diferentes ámbitos de la vida social. Debido al impacto del "núcleo duro" de la desigualdad entre los grupos más vulnerables el esfuerzo realizado por el Estado, las familias y los sujetos particulares sigue resultando insuficiente para poder acceder de forma irrestricta a oportunidades efectivas de inclusión social.

Han sido también importantes los esfuerzos realizados en el ámbito político educativo en la búsqueda de criterios políticos y técnicos orientados a reconocer la pluralidad de identidades y las demandas sociales específicas, sin embargo aún hoy la mayoría de las estrategias implementadas parecen resultar insuficientes a los fines de refrendar la discriminación cultural y la desigualdad socioeconómica que obran como factores de segregación dentro del sistema educativo y así también en los demás ámbitos de la vida política, económica y cultural.

La atención insatisfactoria de las demandas específicas de los pueblos indígenas y de los grupos afrodescendientes en el campo educativo siguen reclamando modelos y propuestas de integración intercultural, dotados de la capacidad para dimensionar adecuadamente las condiciones sociales y culturales heterogéneas de vida, la idiosincrasia y el patrimonio identitario, que constituyen el sustrato referencial de toda política que tenga como finalidad favorecer la objetivación de los intereses y el empoderamiento de los derechos de los ciudadanos. 
Considerando, la separación existente entre las prioridades exclusivamente educativas y el mundo de la vida de los actores sociales, la tarea pediente es clara, se requiere elaborar políticas y modelos de formación que provean a los grupos más desaventajados segundas oportunidades educativas y así también vías intermedias y alternativas de capacitación profesional y técnica. Esto resulta clave para mejorar las perspectivas de inclusión laboral y la adquisición de certificaciones idóneas que se articulen práctica y teóricamente el aprendizaje de oficios, competencias y conocimientos requeridos por el medio social y laboral circundante.

A nuestro juicio, la conjunción de fuerzas y alianzas estratégicas entre la comunidad educativa, el entorno social y los jóvenes mismos puede resultar determinante para concretar los siguientes propósitos:

- elaborar una propuesta educativa capaz de amalgamar estratégicamente a) los intereses y las demandas de los jóvenes y sus comunidades, b) los modelos de desarrollo vigentes a nivel local y c) los distintos actores y sectores sociales como por ejemplo sindicatos, asociaciones comerciales, clubes deportivos, ONG's, instituciones religiosas, etc., que pueden aportar a la organización de los trayectos de formación;

- encauzar efectivamente los procesos de transición hacia instancias de formación superior, a partir de la visibilización de las potencialidades y las restricciones individuales y colectivas de los sujetos juveniles;

- orientar transversalmente los criterios metodológicos y pedagógicos de trabajo con los jóvenes que vinculen aspectos constitutivos y relevantes de la vida social, cultural, afectiva y subjetiva de las personas y favorezcan por ende a la sistematización de competencias psicológicas y disposiciones cognitivas atendiendo a las características específicas de los diferentes sujetos y contextos sociales;

- generar espacios y herramientas de contención e integración social que no se diluyan en la unilateralidad educativa formal - académica a los fines de modelar procesos de formación y elaborar contenidos curriculares significativos;

- actualizar los modelos teóricos y las aplicaciones prácticas de formación en el ámbito de la enseñanza y del aprendizaje y flexibilizar los métodos de organización curricular, de planificación y de evaluación;

- fortalecer los nexos de cooperación intersectorial con referentes privados, no gubernamentales y públicos que intervienen en el apoyo, la orientación y la contención de las demandas específicas que tienen los jóvenes en sus procesos de transición.

Desde el espacio educativo, se debería avanzar en reconocer y validar políticamente las experiencias, las representaciones y los contextos de vida de los jóvenes, lo que no implica únicamente aproximar (ajustando y contextualizando) mejor los dispositivos pedagógicos, didácticos y curriculares hacia este grupo específico, sino que, este desafío estriba en construir espacios de reflexión conjunta y definir criterios de acción congruentes con los contextos novedosos y complejos de vida, las transformaciones sociales y culturales y la multiplicidad identitaria y cultural que influyen de manera diferenciada en y entre los jóvenes, así como en el conjunto de la sociedad.

La escuela en su tarea indelegable de potenciar procesos de participación social y orientar la adquisición significativa de competencias, conocimientos y disposiciones sociocognitivas está obligada a favorecer procesos interculturales de conocimiento y Revista HISTEDBR On-line, Campinas, $n^{\circ}$ 70, p. 05-29, dez. 2016-ISSN: 1676-2584 
transformación histórica y social. Para ello se va tornando cada vez más necesario e inevitable el andamiaje curricular a partir de una lectura multidimensional de la realidad, que servirá de sustrato para definir de modo pertinente recursos didácticos, técnicos y profesionales, los fundamentos metodológicos de trabajo y los perfiles institucionales, máxime cuando nos hallamos interpelados ante el influjo de procesos sociales, culturales, económicos y ecológicos novedosos cada vez más problemáticos a nivel local y global.

Sin lugar a dudas, para la consecución de este nuevo modelo educativo se precisa empoderar a los jóvenes como actores estratégicos de desarrollo y miembros activos de las diferentes comunidades educativas.

La participación de los jóvenes en la gestión de la vida educativa puede suponer en sí misma una experiencia de aprendizaje enriquecedora que posibilite el empoderamiento de los actores en contextos educativos complejos y cambiantes. Esto no implica que la participación casi como una panacea constituya la solución para todos los conflictos engendrados en las sociedades de hoy, sino que por lo contrario, sostenemos que a través del potenciamiento de la participación de los actores y de una intervención más constructiva en la organización del espacio educativo se podrá arremeter contra procesos de exclusión y segregación sociocultural.

La participación a la que nos referimos tiene que ver con la forma en que los jóvenes se involucran en los procesos de toma de decisión que inciden directa e indirectamente en la definición de sus propias trayectorias biográficas, escolares y sociales. Así una escuela y una política pública abierta al entorno comunitario debería ser también consciente de que para lograr el fortalecimiento efectivo de las competencias y los derechos de la ciudadanía se requiere ampliar simultáneamente la solidaridad, el respeto y la participación democrática de toda la comunidad.

Superar la exclusión social y la desafección de la política educativa y social de los actores y sus contextos tiene una importancia capital para poder potenciar el ejercicio de la ciudadanía activa en la vida colectiva. La desafección social, política e institucional provoca que la vida social y pública se plantee y experimente con cierto padecimiento y extravío. La escasez de oportunidades de participación educativa compromete la sustentabilidad del modelo de desarrollo y la cohesión social.

Tomando en atención la complejidad y la vertiginosidad de los cambios que caracterizan a las sociedades latinoamericanas sería importante desarrollar políticas públicas desde una perspectiva transversal y muldimensional provistas de la capacidad de reconocer y vincular los diferentes escenarios donde los jóvenes construyen estrategias para afrontar los desafíos inherentes al proceso de participación social y a la transición hacia el mercado de trabajo y la vida adulta. En esta directriz, se precisa desarrollar políticas públicas basadas en los intereses de los jóvenes capaces de articular los múltiples ámbitos donde los jóvenes construyen sociabilidad, generan alianzas estratégicas, adquieren competencias sociales y culturales, viven la cultura y cognotan su pertenencia social.

Hoy estamos obligados a asumir el compromiso de diseñar dinámicas y escenarios, orientar acciones y concebir programas de formación basados en un mundo complejo y cambiante que demanda permanentemente la reconstrucción de procesos y escenarios de socialización, aprendizaje y enseñanza.

Por todo lo expuesto, se podría concluir que resulta primordial continuar trabajando en el diseño de programas y modelos pedagógicos en articulación con los ámbitos a donde los jóvenes intentan o bien podría abogar por mejorar sus oportunidades de inclusión social. Construir y potenciar desde la cotidianidad de los actores y las instituciones educativas procesos de participación implica indefectiblemente visibilizar en términos pedagógicos y socioculturales las distintas dinámicas de expresión subjetiva, instancias de socialización y 
modelos de referencia identitaria y colectiva en pos de favorecer una verdadera inclusión de los jóvenes y su amplio bagaje de experiencias, iniciativas y expectativas.

\section{Referências}

APARICIO, P. Ch. Bildung, kulturelle Vielfalt und soziale Ungleichheit in Lateinamerika. Die Integration Jugendlicher jenseits sozialer Unterschiede und Ausgrenzungen, en Marcelo Parreira do Amaral \& Karin Amos (Edit.). Internationale und Vergleichende Erziehungswissenschaft. Geschichte, Theorie, Methode und Forschungsfelder. Wasmann: Münster - New York, 2015.

APARICIO, P. Ch. Educación y reformas políticas en América Latina: nuevos y viejos retos de la inclusión social. Los jóvenes en contextos críticos. Debates Latinoamericanos, Año 12, Vol. 1,2014, Abril $\mathrm{N}$ 24, Recuperado el 1 de mayo de 2014 en: http://revista.rlcu.org.ar/numeros/12-24-Abril-2014/documentos/Aparicio.pdf

APARICIO, P. Ch. Inestabilidad y precariedad: Análisis y perspectivas sobre la situación educativa y laboral de los jóvenes en Latinoamérica. Archivos Analíticos de Políticas Educativas, 22 (39), 2014b. Recuperado el 14 de febrero de 2017 en: http://dx.doi.org/10.14507/epaa.v22n39.2014

APARICIO, P. Ch. Educar y trabajar en contextos de precariedad y desigualdad en América Latina. Jóvenes en debate. Revista Latinoamericana de Ciencias Sociales, Niñez y Juventud, 11 (2), pp. 527-546, 2013.

APARICIO, P. Ch. (2012). Education in Latin America: the limits and possibilities of youth social and workforce participation. Beyond the panacea and skepticism. Pedagogía Social. Revista Interuniversitaria, 20, pp. 273-301

APARICIO, P. Ch. Jóvenes y el desafío de vivir en contextos de desigualdad y diversidad. Crisis de las oportunidades de participación educativa y laboral en América Latina. Studia Politicae 19, primavera-verano 2009-2010, pp. 79-100, 2011.

APARICIO, P. Ch. Jóvenes, educación y el desafío de convivir con la diversidad cultural y la desigualdad socioeconómica en América Latina. Revista Antíteses, Ahead of Print do vol. 3, n. 6, 2010. Recuperado el 14 de febrero de 2017 en: http://www.uel.br/revistas/uel/index.php/antiteses

APARICIO, P: Desde la diversidad hacia la desigualdad: ¿destino inexorable de la globalización? A modo de introducción. En Aparicio, Pablo (Coord.) Desde la diversidad hacia la desigualdad: ¿destino inexorable de la globalización? [monográfico en línea]. Revista Electrónica Teoría de la Educación: Educación y Cultura en la Sociedad de la Información. Vol. 9, $\mathrm{n}^{\mathrm{o}} 2$ pp. 5-16, 2008. Recuperado el 21 de marzo de 2017 en: http://www.usal.es/ teoriaeducacion/rev_numero_09_02/n9_02_editorial.pdf

APARICIO, P. Jóvenes, educación y sociedad en América Latina: Los retos de la integración en un contexto de creciente pluralización cultural y segmentación socioeconómica. En Aparicio \& de la Fontaine (Comp.). Diversidad cultural y desigualdad social en América latina y el Caribe: desafíos de la integración global. El Salvador: Ediciones Böll, (pp.155198), 2008b. 
BAUMAN, Z. Life in fragments: Essays in postmodern morality. Oxford: Blackwell, 1993.

BAUMAN, Z. The individualised society. Cambridge: Polity Press, 2001.

BECK, U. ; BECK-GERNSCHEIM, E. (2007). La individualización. El individualismo institucionalizado y sus consecuencias sociales. Buenos Aires: Paidós.

CASTEL, R. Las metamorfosis de la cuestión social. Una crónica del salariado. Buenos Aires, Ed. Paidós, 1999.

CECCHINI, S.; MADARIAGA, A. Programas de transferencias condicionadas: balance de la experiencias de América Latina y el Caribe, Cuadernos de la CEPAL N 25, Santiago de Chile, Comisión Económica para América Latina y el Caribe, 2011.

CECCHINI, S.; R. MARTÍNEZ . "Protección social inclusiva en América Latina. Una mirada integral, un enfoque de derechos", Libros de la CEPAL, No 111. Santiago de Chile: CEPAL, 2011.

CEDLAS (Centro de Estudios Distributivos, Laborales y Sociales). Escaneo de políticas y metanálisis: Juventud y políticas de empleo en América Latina. Buenos Aires: Universidad Nacional de La Plata, 2013.

CEPAL . Panorama Social de América Latina 2013. Santiago de Chile: CEPAL, 2013.

CEPAL. Panorama Social de América Latina 2012. Santiago de Chile: CEPAL, 2012,

CEPAL, OIJ \& IMJUVE . Invertir para transformar. La juventud como protagonista del desarrollo. CEPAL: Santiago de Chile, 2014.

CEPAL \& UNFPA. Informe Regional de Población en América Latina y el Caribe 2011, Invertir en juventud, 2011. Recuperado el 14 de febrero de 2017 en: http://www.eclac.org/cgibin/getProd.asp?xml=/publicaciones/xml/8/47318/P4731.xml\&xsl =publicaciones/ficha.xsl\&base=/publicaciones/top_publicaciones.xsl

DE HOYOS, R, ROGERS, R. Y SZÉKELY, M. Ninis en América Latina: 20 millones de jóvenes en busca de oportunidades. Banco Mundial, Washington, DC, 2016.

DEL POPOLO, F.; LÓPEZ, M. \& ACUÑA, M. Juventud indígena y afrodescendiente en América Latina: inequidades sociodemográficas y desafíos de políticas. Santiago de Chile: CEPAL/UNFPA/OIJ, 2009.

DRIKSON, A. "Contexto global y regional de la Educación Superior en América Latina y el Caribe", en Gazzola, A. y Drikson, A., Tendencias de la educación superior en América Latina y el Caribe, Caracas, IESALC, 2008. Recuperado el 2 de noviembre de 2014 en: http://www.iesalc.unesco.org.ve/index.php?option=com_content\&view=article\&id=2\&Ite mid=408\&lang=es Consultado el 21 de abril de 2014).

DUBET, F. Repensar la Justicia Social contra el mito de la igualdad de oportunidades. Buenos Aires: Siglo XXI, 2011.

DURU -BELLAT, M. ; VERLEY, É. "Les étudiants au fil du temps.: context et repères 
institutionnels", en Les étudiants en France. Histoire et sociologie d' une nouvelle jeunesse, Presses Universitaires de Rennes, 2009.

FORNET - BETANCOURT, R. "Interculturalidad: asignatura pendiente de la filosofía latinoamericana. Para una revisión crítica de la filosofía latinoamericana más reciente". En Erasmus. Río Cuarto. ICALA. Año V. № 1 / 2, 169 -192, 2003.

GARCÍA HUIDOBRO, J. "Desigualdad educativa y segmentación del sistema escolar. Consideraciones a partir del caso chileno", en Revista Pensamiento Educativo, Vol. 40, $\mathrm{N}^{\circ}$ 1, junio, 2007. Disponible en: Http://mt.educarchile.cl/MT/jjbrunner/ archives/ libros/COX/PENSAMIENTO_EDUCATIVO_40-I.pdf. Consultado el 22 de abril de 2014.

GASPARINI, L., M. HORENSTEIN, E. MOLINA Y S. OLIVIERI. "Income Polarization: An Exploratory Analysis for Latin America". Documento mimeografiado. CEDLASPNUD, 2009.

GARCÍA-HUIDOBRO, J. Una nueva meta para la educación latinoamericana en el bicentenario, en: Marchesi, Álvaro / Tedesco, Juan Carlos / Coll, César (Ed.), Calidad, equidad y reformas en la enseñanza, Madrid: OEI-Santillana, pp.19-34, 2009.

GENTILI, P. Marchas y contramarchas. El derecho a la educación y las dinámicas de exclusión incluyente en América Latina, en Revista Iberoamericana de Educación Vol. 49, pp.19-57, 2009

GROSFOGUEL, R. "World-System Analysis and Postcolonial Studies: A Call for Dialogue from the $=$ Coloniality of Power ${ }^{6}$ Approach", in Revathi Krishnaswamy and John C. Hawley, eds., The Postcolonial and the Global. Minneapolis: University of Minnesota Press, pp. 94104, 2008

HOPENHAYN, M. Desafios para avanzar en mayor equidad desde la educacion en América Latina y el Caribe. México: EPT/PRELAC, 2013.

JACINTO, C. (Coord.). Incluir a los jóvenes. Retos para la educación terciaria técnica en América Latina. Buenos Aires: IIEP - UNESCO, 2013.

KREHOFF, B. Multiculturalismo, indigenismo y derechos indígenas, en Aparicio, P. y de la Fontaine, M. (comps.). Diversidad cultural y desigualdad social en América Latina y el Caribe: Desafíos de la integración global (71-83), El Salvador: Fundación Heinrich Böll, 2008

LÓPEZ-CALVA, L. F. y N. Lustig (Eds.). Declining Income Inequality in America: A Decade of Progress? Baltimore: MD. Brookings Institution Press, 2010.

Maldonado Varela, C. \& Palma Rocco, A. La construcción de pactos y consensos en materia de política social: Aportes para un marco de análisis. Serie Políticas Sociales N 179. Santiago de Chile: CEPAL \& Cooperación Alemana, 2013.

OCAMPO, J. A. Las concepciones de la política social: universalismo versus focalización, in: Nueva Sociedad Vol. 215, pp. 36-61, 2008.

OIJ, BID, CAF, PNUD, CEPAL \& . El futuro ya llegó. 1a Encuesta Iberoamericana de Revista HISTEDBR On-line, Campinas, $n^{\circ}$ 70, p. 05-29, dez. 2016-ISSN: 1676-2584 
juventudes, 2012.

Poggi, M. La educación en América Latina: logros y desafíos pendientes. Documento básico. Buenos Aires: Fundación Santillana, 2014.

PNUD. Informe sobre Desarrollo Humano 2009. Superando Barreras: Movilidad y Desarrollo Humanos. Nueva York: PNUD, 2009.

REGUILLO, R. Culturas Juveniles. Formas políticas del desencanto. Buenos Aires: Siglo XXI Editores, 2012.

ROMERO, J. Conocimiento escolar, ciencia, institución y democracia. Archivos Analíticos de Políticas Educativas, 22 (21), 2014. Recuperado el 3 de mayo de 2014 en: http://dx.doi.org/10.14507/epaa.v22n21.2014.

SANTOS REGO, M. \& APARICIO, P. Ch. "Educación, juventud y convivencia intercultural. Reconstruir la ético de lo común", en E. Vila Merino, V. Martín Solbes, M. T. Castilla Mesa \& J. E. Sierra Nieto (Coord.) Ética, educación y convivencia. Málaga: Ediciones Aljibe, pp. 83-97, 2014

SANTOS REGO, M.; LORENZO MOLEDO, M. \& APARICIO, P.Ch. "Cambio en la universidad y las previsiones de una formación más intercultural de los jóvenes". Innovación Educativa, Vol. 10, N. 50, Pp. 43-53, 2010.

SANTOS REGO, M. A. y Lorenzo Moledo, M. (eds.). Estudios de pedagogía intercultural, Barcelona: Octaedro, 2012.

SOETERIK, I. M. Desafíos académicos y socioculturales para la absorción del concepto educación inclusiva en Brasil. Innovación Educativa, Vol. 10, N. 50, Pp. 19-29, 2010.

TIRAMONTI, G. "Dimensiones en la discusión de la problemática de la escuela media", en E. Tenti Fanfani (coord.) La escolarización de los adolescentes: desafíos culturales, pedagógicos y de política educativa Instituto Internacional de Planeamiento de la Educación. Buenos Aires: IIPE -Unesco, pp. 163-190, 2012.

TORRES, C. A. Después de la tormenta neoliberal: la política educativa latinoamericana entre la crítica y la utopía, en: Revista Iberoamericana de Educación Vol. 48, pp. 207-229, 2008.

UNESCO. Informe 2012. Jóvenes y las competencias: trabajar con la educación. Santiago de Chile: UNESCO/ PREALC., 2012.

UNICEF \& UNESCO. Iniciativa Global por los Niños fuera de la escuela. Panamá: UNICEF, 2012.

URQUIOLA, M. (2009). "The Intergenerational Transmission of Education in Latin America. What are the Key Constraints?" Documento de apoyo del Informe Regional sobre Desarrollo Humano en América Latina y el Caribe, 2010.

SITEAL . Informe sobre tendencias sociales y educativas en América Latina. Buenos Aires: OEI-IIPE, 2006. 
VILA MERINO, E. "Ser diciendo, educar haciendo: repensando las políticas interculturales en Latinoamérica. Una introducción." Innovación Educativa, Vol. 10, N. 50, Pp. 5-11, 2010

VILA MERINO, E. \& Alvarez Jiménez, V. "Educarnos con otras voces Alteridad política e intercultural de las mujeres indígenas. Innovación Educativa, Vol. 10, N. 50, Pp. 13-17, 2010 .

WELLER, J. \& ROETHLISBERGERG, C. La calidad del empleo en América Latina. Santiago de Chile: CEPAL, Naciones Unidas, 2011.

\footnotetext{
${ }^{1}$ Fuente: Comisión Económica para América Latina y el Caribe (CEPAL) sobre la base de tabulaciones especiales de las encuestas de hogares de los respectivos países. Pág. 41 a/ Sólo áreas urbanas.

${ }^{2}$ Fuente: CEPAL \& UNFPA (2011). Informe sobre juventud, CEPAL: Santiago de Chile, pp. 136 -137

${ }^{3}$ Fuente: Comisión Económica para América Latina y el Caribe (CEPAL) (2012), sobre la base de tabulaciones de las encuestas de hogares de los países.
}

${ }^{4}$ En razón a la dimensión histórica, política y social del currículum como espacio de lucha y herramienta de poder, Romero (2014:16-17) postula que "las relaciones de conocimiento son traducidas como relaciones de poder entre grupos, en concreto entre las "voces" imperantes y las acalladas por su supremacía. En semejante tesitura, el compromiso político en pro de la justicia se canaliza hacia la impugnación del código de significación preponderante, dentro del cual descollaría la ciencia. La modernidad habría apuntalado la preeminencia de ésta última frente a otros marcos de interpretación, al investirla con una imaginada dignidad trascendental e inmaculada que le otorgaría el monopolio de la objetividad y la verdad. Este "absolutismo" gnoseológico tendría consecuencias opresivas, al excluir la diferencia y ocultarla tras el pesado manto del silencio. Sin embargo, el dogma de la razón pura es una falacia. Toda actividad cognoscitiva, incluida la científica, es una práctica social, histórica y culturalmente determinada. Al decir de Clifford Geertz, los patrones de conocimiento son siempre ineluctablemente locales. Lo que asomaría en realidad por detrás de las reivindicaciones de universalismo y objetividad no sería sino el etnocentrismo y los intereses disfrazados de las élites rectoras."

${ }^{5}$ Fuente: Comisión Económica para América Latina y el Caribe (CEPAL), sobre la base de tabulaciones especiales de las encuestas de hogares de los respectivos países. Pág. 75

a/ Solo incluye población urbana.

b/ Promedios ponderados.

${ }^{6}$ La idea central se fundamenta en la redefinición del concepto de inclusión educativa que, en América Latina, ha tenido diferentes desarrollos, acepciones y aplicaciones práxicas que van desde la implementación de políticas instrumentales y pragmáticas gestadas bajo el principio de mercado educativo (oferta - demanda) hasta reformas políticas universales, populares y de fuerte carácter democratizador que han tenido principal apogeo en el momento de recuperación de las competencias sociales de los Estados durante el período 20032009 (Aparicio, 2008b, CEPAL \& OIJ, 2008).

Recebido: Fevereiro/2017.

Aprovado: Abril/2017. 